\title{
HUMAN HEALTH PROBLEMS AND CLASSIFICATION OF THE MOST TOXIC PESTICIDES
}

\author{
Venelin Terziev ${ }^{1}$ and Stoyanka Petkova - Georgieva ${ }^{2}$ \\ ${ }^{1}$ Full Member of the Russian Academy of Natural History, Professor, Eng., D.Sc. (National \\ Security), D.Sc. (Economics), D.Sc. (Social Activities), Ph.D., Russian Academy of Natural History, \\ Moscow, Russia, Vasil Levski National Military University, Veliko Tarnovo, Bulgaria University of \\ Rousse, Rousse, Bulgaria, terziev@skmat.com \\ ${ }^{2}$ Associate Professor, Ph.D., University „Prof. d-r Assen Zlatarov” - Bourgas, Bulgaria, \\ s.p.petkova@gmail.com
}

\begin{abstract}
The present study is dedicated to the human health problems and classification of the most toxic pesticides. Pesticides are a wide range of chemicals with different degree of hazard, from extremely to slightly hazardous. Highly hazardous pesticides may have acute or chronic toxic effects. Their widespread use has caused health problems and fatalities in many parts of the world, often as a result of occupational exposure and accidental or intentional poisonings. Environmental contamination can also result in human exposure through consumption of residues of pesticides in food and, possibly, drinking-water. Recommended classification of pesticides by hazard; carcinogenicity; mutagenicity; reproductive toxicity; listing under the Stockholm Convention on Persistent Organic Pollutants, the Rotterdam Convention on the Prior Informed Consent Procedure for Certain Hazardous Pesticides and Industrial Chemicals in International Trade or the Montreal Protocol on Substances that Deplete the Ozone Layer; or evidence of severe or irreversible adverse effects on human health.
\end{abstract}

Keywords: human health problems, toxic impact, pesticides, ecosystem.

\section{INTRODUCTION}

For many decades, pesticides have been used worldwide as a mean to increase agricultural output, fight pests and control tropical diseases. However, with increasing and prolonged use, also negative impacts became noticeable such as an increase of disease rates, infertility and sometimes death, or environmental impacts including contamination of local water supplies, global transport and bio-accumulation of persistent organic pollutants (POPs), or loss of income to farmers whose products contains unacceptable concentrations of pesticide residues to be fit for sale.

There's another problem: over the years, pesticides have been accumulated, particularly in developing countries, and most of them with the expiate date of use constitutes a threat to health and environment.

Several international environmental conventions aim to protect human health and the environment. Those are related to generation and trade of chemicals and wastes, included pesticides. The Food and Agriculture Organisation (FAO) of the United Nations (UN) has taken the lead in developing and implementing appropriate solutions to the problem of obsolete pesticide stocks in the developing world. 


\section{CLASSIFICATION OF THE MOST TOXIC PESTICIDES}

Although, there are many available technologies for adequate disposal of obsolete pesticides is important to evaluate their suitability for the disposal of bulk quantities of obsolete pesticides according to local conditions. The main criteria to choose the most appropriate technology are:

- Environmental soundness of the technology;

- Occupational safety for operators;

- Technical feasibility for destruction of bulk quantities of obsolete pesticides;

- Suitability for common circumstances in developing countries;

- Cost-effectiveness.

A particular technique may be acceptable for one type of obsolete pesticides, but absolutely unsuitable for another type. It is fundamental to evaluate the situation case-by-case in the field and consider the technology or combination of the technologies which is most suitable depends on the type and quantity of the pesticides to be disposed of (Potera, 2007a).

In addition, developing countries need to create internal capacity to sound management of pesticides in order of prevent future accumulation through regulations and its enforcement, environmental protection, public health awareness among other interventions (Schafer et al., 2007b).

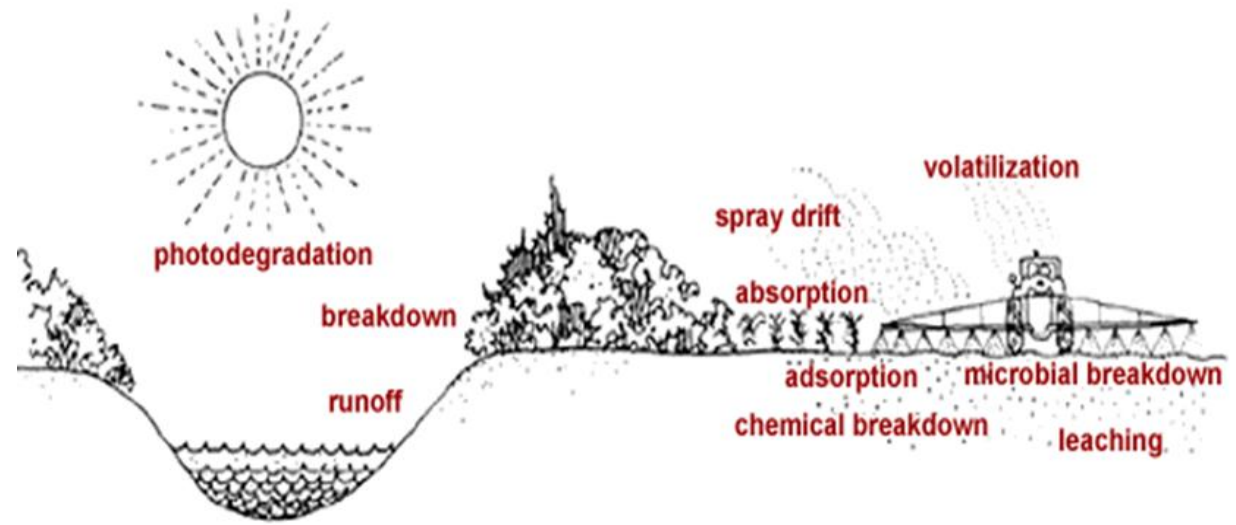

Figure 1. Degradation of Pesticides in the Ecosystem. Source : www.agf.gov.bc.ca

Pesticides may be classified in a number of ways and these classifications can provide useful information about the chemistry of the pesticides. Broadly speaking pesticides can be classified either in terms of target or in terms of chemical structure.

Many pesticides are not biodegradable and due to bioaccumulation, can enter into food chain and ultimately affect human and animal health (Figure 1). Environmental exposure of humans to pesticides through ecosystems may occur during agricultural practices, consumption of food materials or air inhalation etc. Adverse health effects include acute and persistent injury to the nervous system, lung damage, injury to reproductive organs, and dysfunction of the immune and endocrine systems, birth defects and cancer. A better understanding of the patterns of exposure, the links between the animal toxicology and human health effects will improve the evaluation of the risks posed by pesticides to the ecosystem. There is need to educate all stakeholders on responsible use of pesticides and proper application of integrated pest management programs (World Health Organization, 2003b- 2004). This will positively reflect on human health, biodiversity and ecosystem management and minimize pesticides environmental problems. International conventions such as the Rotterdam Convention, the Chemical Weapon Convention, Stockholm Convention and the Montreal Convention are some of efforts of the international community to address pesticides environmental issues, in all the above convections, efforts are directed either on total ban or restricted use of some classified pesticides (Terziev, Petkova- Georgieva, 2019-a).

- Target

Under this classification of the pesticides can be classified according to their respective functions, there are some pesticides for example Aldicarb, which control more than one class of pests and may be considered in more than one pesticide class 
Table1. Pesticides Classification by Target.

\begin{tabular}{|c|c|c|}
\hline Pesticide class & Primary target/action & Example \\
\hline Acaricide & Mites & Aldicarb \\
\hline Algaecide & Algae & Copper sulphate \\
\hline Attractant & Attracts wide range of pests & Pheromones \\
\hline Avicide & Birds & Amino pyridine \\
\hline Bactericide & Bacteria & Streptomycin \\
\hline Bio pesticide & Wide range of organisms & Bacillus thuringiensis \\
\hline Defoliant & Removes plant foliage & Tribufos \\
\hline Fumigant & Wide range of organisms & Aluminium phosphide \\
\hline Fungicide & Fungi & Azoxystrobin \\
\hline Herbicide & Weeds & Atrazine \\
\hline Insecticide & Insects & Aldicarb \\
\hline Nematicide & Nematodes & Aldicarb \\
\hline Rodenticides & Rodents & Warfarin \\
\hline Termiticide & Termites & Fipronil \\
\hline
\end{tabular}

Source: www.edis.ifas.ufl.edu.

\section{- Chemical Structure}

Based on chemical structure, pesticides are classified depending on their chemical compositions and are classified as either organic or inorganic pesticides.

- Inorganic Pesticides

Inorganic pesticides are simple compounds which have a crystalline salt-like appearance, are environmentally stable and usually soluble in water. These were the earliest chemical pesticides and included compounds of substances such as Sulphur, Aluminium phosphide, lime, arsenic, copper and mercury among others. They are generally toxic and have the ability to remain in the environment for a long period of time.

\section{- Organic Pesticides}

Organic pesticides are chemicals that have carbon as the basis of their molecular structure and are more complex than inorganic pesticides. They are usually insoluble in water but ready soluble in fatty acids. Organic pesticides can be subdivided into two additional groups: the natural and synthetic organics pesticides, while the natural organic pesticides are derived from naturally occurring sources such as plants pyrethrum, synthetic organic pesticides on the other hand, are produced artificially by chemical synthesis. Most of the modern pesticides are organic chemicals often with oxygen, phosphorus, or sulphur in their molecules. Pesticides in this class are further classified as either fumigants, organochlorines, organophosphates or carbamates.

\section{$\checkmark$ Fumigants}

Generally, fumigants are small molecular compounds that easily penetrate in some materials and are widely used to sterilize the soil and prevent degradation of stored grains, they include; carbon tetrachloride, methyl bromide, ethylene dibromide among other.

Carbon tetrachloride is also used as an industrial cleaning solvent and is also widely used as a feedstock substance in the production of other chemicals. Due to its ability to deplete the ozone, it has been classified as a controlled substance under the Montreal Protocol where its use is restricted to the use as a feedstock which results in very small emissions while others such as methyl bromide which is a broad spectrum 
pesticide, under the same protocol is placed under phased out total ban.

Methyl bromide is manufactured from naturally occurring bromide salts and is often produced as a byproduct of other bromide manufacturing processes. It is used as a soil fumigant to sterilize the soil by killing a vast majority of soil organisms and in the end is emitted to the atmosphere. Methyl bromide is a toxic material and because it dissipates so rapidly to the atmosphere, it is most dangerous at the actual fumigation site itself. Human exposure to high concentrations of methyl bromide can result in central nervous system and respiratory system failure, as well as specific and severe deleterious actions on the lungs, eyes, and skin.

\section{$\checkmark$ Organochlorines}

Organochlorines pesticides are generally, persistent and toxic pollutants composed primarily of carbon, hydrogen, and chlorine. The chlorine atoms prevent the organic compounds from being rapidly degraded in the environment, thus these pesticides are persistent and active for a long period of time after application and as a result their use and applications are either banned or restricted in some countries. Organochlorines are mostly used as insecticides and their use ranges from pellet application in field crops to sprays for seed coating and grain storage. DDT being the cheapest, lasting and effective have gained demand and used worldwide among the Organochlorines. (www.pesticideinfo.org). Because of its persistent in the environment, DDT for example was banned for use in the United States of America in 1973; its use and production was also banned under the Stockholm Convention, with an exception made allowing DDT only for the public health interest use in the control the mosquitoes. Due to this DDT use is currently increasing in some countries where malaria is prevalent.

Toxicity is largely due to stimulation of the central nervous system. Organochlorines disturb the neuronal membrane causing hyper excitability of the nervous system. Specifically, Organochlorines inhibit GABAmediated chloride influx in the central nerves system (CNS); these changes can result in agitation, confusion, and seizures (Newton et al., 1986).

\section{$\checkmark$ Carbamates}

Carbamates are chemically similar in structure to organophosphates, only that whereas organophosphates are derivatives of phosphoric acid, carbamate are derivatives of carbamic acid and have a general formula shown below where $\mathrm{R}=\mathrm{O}$ is an alcohol or phenol and $\mathrm{R} 1$ is hydrogen or a methyl group (Figure 2).

$\mathrm{OH}$

\section{R-O -C-N-R1}

Figure 2. Structure of Carbamates.

Pesticides in this group are used for vector control and include chemicals such as carbaryl used for dusting live stocks for control fleas, propoxur for use against insect pests and others for bee and wasp control. Carbamates vary in their spectrum of activity, mammalian toxicity and persistence. They are relatively unstable compounds that break down in the environment within weeks or months; they are commonly used as surface sprays or baits in the control of household pests and also pose a relatively high risk for human poisoning.

The mechanism of carbamates poisoning involves carbamylating of the active site of acetycholinesterase leading to the inactivation of this essential enzyme which has an important role in nervous system of humans, and other animal species. In the presence of inhibitors, acetycholinesterase becomes progressively inhibited and is not further capable of hydrolyzing acetylcholine to choline and acetic acid; consequently, acetylcholine accumulates at cholinergic receptor sites and produces effects equivalent to excessive stimulation of cholinergic receptors throughout the central and peripheral nervous system, (Ecobichon, 2001).

\section{$\checkmark$ Organophosphates}

Organophosphates are esters of phosphoric acid and its derivates and are considered to pose a greater human health risk than other families of pesticides. The general chemical structure of an organophosphate comprises of a central phosphorus atom $(P)$ and the characteristic phosphoric $(P=O)$ or thiophosphoric $(P=S)$ bond and a leaving group, which can be replaced by the oxygen of serine in the acetylcholine esterase (AcHE) active site (Figure 3). 
(a)<smiles>CCOP(C)(=O)NC</smiles>

(b)<smiles>CC(C)C(C)(C)O[PH](C)(=O)=O</smiles>

(c)<smiles>CC(C)OP(C)(=O)F</smiles>

Figure 3. Structure of Organophosphates - Warfare Agents.

The first organophosphates were synthesised in the 19th century and has since formed a large group of chemicals used for protecting crops and livestock. At the beginning of the Second World War, the development of organophosphates switched to highly toxic compounds which were employed as nerve warfare agents, for example Soman and Tabun, after the war, the development of organophosphates was again oriented towards the development of less toxic compounds (Beketov et al, 2007).

The primary mechanism of Organophosphates toxicity is the inhibition of acetylcholine esterase (AcHE) in the central and peripheral nervous system, leading to a variety of short-term and chronic. The rate of AcHE inhibition depends on the leaving group; higher tendency of leaving results in higher affinity of the inhibitor to the enzyme. In very toxic warfare agents the leaving group contains fluorine $(F)$, which has high tendency to hydrolyse while in less toxic organophosphates, the leaving group usually contains alkyl or aryl groups (Figure 4) (Liebich et al., 2003).

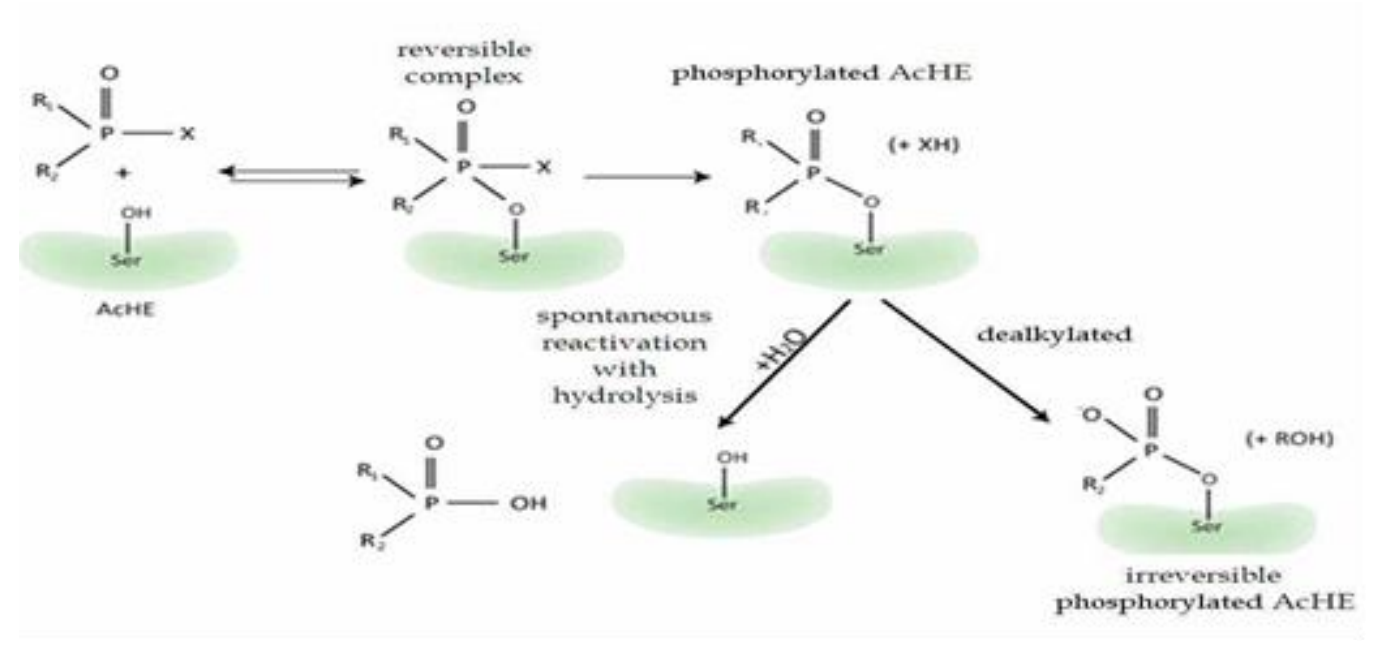

Figure 4. The binding of Organophosphates to AcHE.

The present study is dedicated to the human health problems and classification of the most toxic pesticides. Pesticides are a wide range of chemicals with different degree of hazard, from extremely to slightly hazardous. Highly hazardous pesticides may have acute or chronic toxic effects (Schreck et al., 2008). Their widespread use has caused health problems and fatalities in many parts of the world, often as a result of occupational exposure and accidental or intentional poisonings (Lorenz, Eric, 2009). Environmental contamination can also result in human exposure through consumption of residues of pesticides in food and, possibly, drinking-water. Recommended classification of pesticides by hazard; carcinogenicity; mutagenicity; reproductive toxicity; listing under the Stockholm Convention on Persistent Organic Pollutants, the Rotterdam Convention on the Prior Informed Consent Procedure for Certain Hazardous Pesticides and Industrial Chemicals in International Trade or the Montreal Protocol on Substances that Deplete the Ozone Layer; or evidence of severe or irreversible adverse effects on human health.

Accumulation of obsolete pesticides is a problem in developing countries. On one hand public health and environmental authorities strongly recommend removal of stockpiles and site decontamination; On the other hand, site decontamination and cleanup are very expensive processes and financial resources are not available.

A methodology for prioritizing sites and treating them sequentially, as budgetary resources are made available is an important tool to tangle the problem of obsolete pesticides in developing countries. The Tunisian government implemented an integrated approach correlating the information on eco-regions and biodiversity at risk, their proximity to stockpiles, the relative toxic hazards of the chemicals in stockpiles, and the conditions of the containers in which they are stored. 


\section{THE PROBLEM OF TOXIC PESTICIDES IMPACT ON HUMAN HEALTH THE ECOSYSTEM}

The accumulation of obsolete pesticides mainly in developing countries, over the years was caused by many factors such as: unsuitable products and packaging, excessive donations and purchases, poor stock management, inadequate coordination between donors' agencies, commercial interests of private sector and pesticides bans. It is strongly recomended the chemical safety procedures to be followed and observed when there is a need of special treatment for purifying the ecosystem from obsolete pesticides (Figure 5).

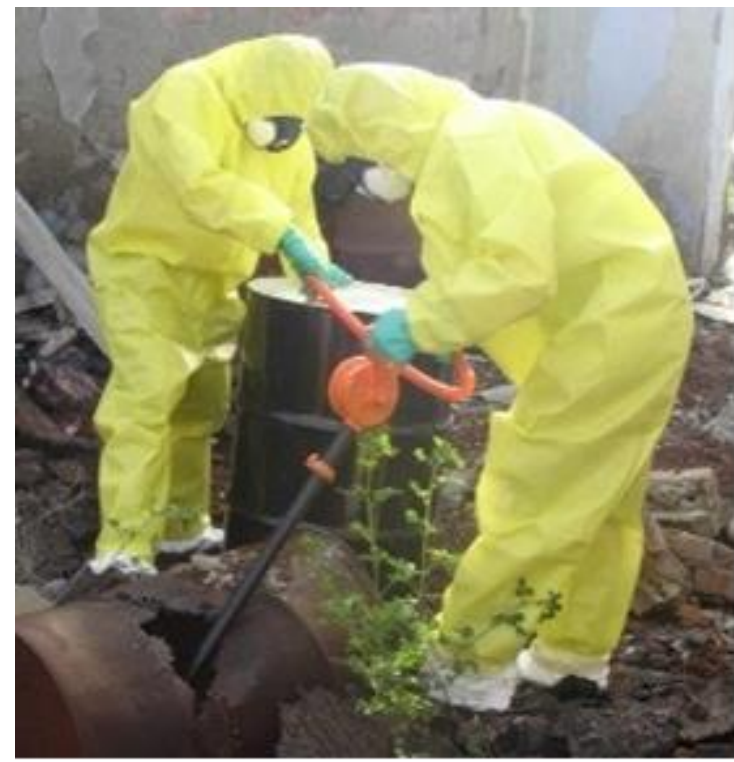

Figure 5. Safeguarding of obsolete pesticides.

According to World Bank (The World Bank, 2013): "At appraisal, the amount of publicly held obsolete pesticides stockpiled across Africa, was estimated at 50,000 metric tons with additional quantities leaking into the environment, contaminating soil, water, air and food sources. In Africa, a total of 51,794 tons of obsolete pesticides had been identified by the Food and Agriculture Organization (FAO)".

This rough estimation did not include contaminated soils and was intended to be refined through the countryspecific detailed inventories planned under Africa Stockpiles Program (ASP) (Yadav, 2007c).

Many of the accumulated obsolete pesticides are persistent organic pollutants POP's which incorporates highly toxic properties (Relyea, 2003a). Other characteristics of these pesticides are resisted degradation, bio-accumulate and can be transported through air and water across international boundaries and deposited far from their place of release so contaminated the environment.

Besides, in many developing countries the stocks are stored in the open air or in inappropriate storage conditions. Containers are often inadequate and leaking or corroded, though contaminated the drinking water sources and irrigation schemes.

Obsolete pesticides are defined as those pesticides that can no longer be used for their intended purpose use and therefore must be disposed off.

Obsolete pesticides include:

- Outdated technical pesticides or formulations (generally products have a shelf-life of two years from the date of release);

- Pesticides, that have been withdrawn through banning or that have been severely restricted;

- Deteriorated products:

- Those that have undergone physical or chemical changes that result in phytotoxic effects on the target crop, or an unacceptable hazard to human health or environment.

- Those that have undergone an unacceptable loss of biological efficacy.

- Those whose physical properties have changed to such an extent that it can no longer be applied with standard application equipment. 
- Unwanted pesticides, even though they still can be used;

- Unidentified products;

- Products contaminated with other substances.

It is also considered obsolete pesticides other substances like pesticides wastes generated in fire events or accidents, materials strongly contaminated with pesticides and residues resultant from production or formulation of pesticides.

\section{CONCLUSION}

It is generally agreed that the problem of stockpiles of obsolete pesticide has arisen as a result of an inappropriate actions of many players including donor agencies, industry, governments, advisors and others. To date disposal operations have been funded by some national aid agencies, some contributions from the chemical industry and some international agencies (Todorov, 2018; Todorov, 2015).

It is fundamental that governments implement plans of action to minimize the problem of stockpiles of obsolete pesticides in developing countries and prevent for further accumulations. The management of pesticides in developing countries need to be improved trough an effective control over the agricultural and public health pesticides, their application in agriculture and public health, the disposal of obsolete stocks and empty pesticide containers, storage facilities, public information, environmental protection, regulation and its enforcement.

The Food and Agriculture Organization (FAO) provided technical support and practical guidelines on the environmentally sound management of obsolete pesticides to ensuring that all technical aspects are executed in accordance with appropriate international laws and standards, and that countries receive the technical assistance they require as and when it is needed to improve their management of pesticides.

\section{REFERENCE LIST}

Terziev, V., Petkova - Georgieva, S. (2019). The performance measurment system key indicators and the determinants impact on the level of decentralization using as an example a subdivisional unit from the Bulgarian social health and care experience. // Proceedings of SOCIOINT 2019-6th International Conference on Education, Social Sciences and Humanities 24-26 June 2019- Istanbul, Turkey, International Organization Center of Academic Research, Istanbul, Turkey, 2019, pp. 515-524, ISBN: 978-605-82433-6-1.

Terziev, V., Petkova- Georgieva, S. (2019a). A research study of nonlinearity experiencing in the rate of current account deficit to the Bulgarian health and care national product. // Proceedings of SOCIOINT 2019- 6th International Conference on Education, Social Sciences and Humanities 24-26 June 2019Istanbul, Turkey, International Organization Center of Academic Research, Istanbul, Turkey, 2019, pp. 525-533, ISBN: 978-605-82433-6-1.

Beketov, M.A., Schäfer, R.B., Marwitz, A., Paschke, A., Liess, M. (2007). Long-term stream invertebrate community alterations induced by the insecticide: Effect concentrations and recovery dynamics. Science of the Total Environment 405 Casabé, N., Piola, L., Fuchs, J., Oneto, M.L., Pamparato, L., Basack, S., Giménez, R., Massaro, R., Papa, J.C., Kesten, E. (2007): Ecotoxicological Assessment of the Effects of Glyphosate and Chlorpyrifos in an Argentine Soya Field. Journal of soil sediments 7.

Todorov, M. (2018). Recent advances in computational chemistry for identification of ligands for biological receptors: interdisciplinary aspects, Medical Science Pulse 2018 (12) 1, pp. 12-15, DOI: 10.5604/01.3001.0011.6670, ISSN: 2544-1620.

Todorov, M.(2015). Computational tools for prediction of nuclear receptor mediated effects. East. Acad. J., 2015, 1, pp. 46-56, ISSN:2367-7384.

Liebich, J., Schäffer, A., Burauel, P. (2003). Structural and Functional Approach to Studying Pesticides Sideeffects on Specific Soil Functions, Environmental Toxicology and Chemistry.

Lorenz, Eric S. (2009). Potential Health Effects of Pesticide, Communications and Marketing.

Newton, I., Bogan, J. A. and Rothery, P. (1986): Trends and Effects of Organochlorines Compounds in Sparrow Hawk Eggs, Journal of Application Ecology 23. 
Potera, C. (2007a). Agriculture: Pesticides Disrupt Nitrogen Fixation. Environment Health Perspective 115.

Relyea, R.A. (2003a). Predator Cues and Pesticides: A double Dose of Danger for Amphibians. Ecological Applications 13.

Schafer, R.B., Caquet, T., Siimes, K., Mueller, R., Lagadic, L., Liess, M. (2007b). Effects of Pesticides on Community Structure and Ecosystem Functions in Agricultural Streams of Three Bio geographical Regions in Europe, Science of the Total Environment 382.

Schreck, E., Geret, F., Gontier, L., Treilhou, M. (2008). Neurotoxic Effect and Metabolic Responses Induced by a Mixture of Six Pesticides on the Earthworm, Chemosphere 71.

World Health Organization (2003b). The World Health Report 2003, Shaping the Future, Geneva.

World Health Organization (2004). The Prevention of Mental Disorders: Effective Interventions and Policy Options, Geneva.

Yadav, SK (2007c). Soil Ecology, New Delhi, APH Publishers. 